\title{
A retórica da infelicidade: laço social e leitura em livros escolares do cânone republicano ${ }^{1}$
}

\author{
Antônio Augusto Gomes Batista*
}

\section{Resumo}

Este artigo tem dois principais objetivos. Em primeiro lugar, ele é animado pelo interesse em chamar a atenção de pesquisadores para tópico pouco estudado pela pesquisa brasileira sobre o cânone republicano para a escola elementar: a presença de textos sobre a morte, a contingência, a tristeza, o que aqui designo "retórica da infelicidade". Em segundo lugar, o artigo é animado pelo objetivo de descrever os procedimentos retórico-

* Coordenador de Pesquisas do Cenpec; professor do Programa de Pós-Graduação da Faculdade de Educação da Universidade Federal de Minas Gerais (UFMG), Brasil. Bolsista do CNPq. antonio. batista@cenpec.org.br -discursivos que sustentam a abordagem dessa temática e para isso analisa um texto pertencente ao códice republicano. Essa análise permitirá, nas conclusões do trabalho, esboçar diretrizes teórico-metodológicas para o estudo do poder formativo dos textos escolares.

\section{Palavras-chave}

manuais escolares; escola elementar; Olavo Bilac; leitura. 


\title{
The rhetoric of unhappiness: social bondage and reading in textbooks from the Republican canon
}

\begin{abstract}
This article has two main objectives. The first is to call researchers' attention to a subject that is very little studied in Brazil regarding the Republican canon in elementary schools: the presence of texts about death, contingency and sadness- what I call here "rhetoric of unhappiness." The second objective is to describe the rhetorical-discursive procedures used to support discussions of these themes through the analysis of a text from the Republican codex. In the conclusion of this paper this analysis allows for an outline of theoretical and methodological guidelines for studying the formative power of school textbooks.
\end{abstract}

Key words school textbooks; elementary school; Olavo Bilac; reading. 
Este artigo apresenta parte de um último estudo de uma série de investigações sobre livros escolares de leitura utilizados no Brasil, das últimas décadas do século XIX às primeiras do século XX. Sua origem reside numa insatisfação com o modo como, ao longo dessas investigações, abordei uma das principais funções atribuídas então aos livros: a aculturação das crianças².

Utilizo o termo "aculturação", a fim de me referir a dois fenômenos inter-relacionados. Por um lado, a um esforço deliberado da escola para a integração dos meninos e das meninas a um espaço social (tal como um conjunto de agentes e instituições sociais lutavam para representá-lo e assim o apresentavam em suas práticas e livros educativos), por meio da criação e da transmissão de ideais capazes de promover um laço social. Por outro lado, utilizo o termo para designar um esforço de transmissão de modos de produzir significados na leitura, de forma a assegurar o trabalho escolar de aculturação, buscando inserir as crianças numa comunidade interpretativa ou de leitores (Fish, 1980).

$\mathrm{Na}$ construção da escola elementar republicana brasileira, o exercício dessa função por meio dos livros de leitura assumiu uma configuração que se manteve mais ou menos estável dos primeiros anos após a proclamação da República até meados dos anos 1970, quando, dentre outros fatores, emergiu, no cenário educacional, a crítica ao caráter ideológico dos textos escolares (ver, por exemplo, Faria, 1980; Lajolo, 1982; Nosella, 1979) e se evidenciou que a contribuição da escola para a reprodução das desigualdades sociais se realiza também por seu projeto de ser a instituição destinada a inserir todos, do mesmo modo, no interior de uma "civilização".

$\mathrm{O}$ artigo tem dois principais objetivos. Em primeiro lugar, ele é animado pelo interesse em chamar a atenção de pesquisadores para uma temática pouco estudada pela pesquisa brasileira sobre o cânone escolar republicano. Ela reside na recorrência, nos livros de leitura destinados à escola elementar, daquilo que aqui designarei uma "retórica da infelicidade". Em segundo lugar, o artigo é animado pelo objetivo de descrever os procedimentos retóricos que sustentam a abordagem dessa temática, para o que analiso um texto pertencente ao códice republicano ${ }^{3}$.

\section{Uma nova retórica para as crianças}

No início do século XX, José Lins do Rego viveu uma nova experiência de leitura, distinta das que vivera anteriormente na escola, diferente da gran-
2. Para uma análise de outras funções dos manuais no período, cf. Batista; Galvão (2009).

3. A presença, na escola, dos tipos de textos de que trato aqui é que me faz estabelecer essa demarcação, apesar das modificações que a escola viveu no período. 
de parte dos relatos disponíveis de outros estudantes ${ }^{4}$.

Enquanto fazia suas lições, Carlos de Melo, de Doidinho (Rego, [1933]1977), personagem que reflete as experiências de seu autor, podia escutar as leituras em voz alta dos colegas que estavam no livro mais avançado. Trata-se de Coração, de Edmundo de Amicis (19-). Carlinhos ansiava pela leitura desse livro5:

... o meu grande ideal de aluno estava no Coração. [...] tudo me parecia passagens de um romance admirável. [...] Ficava às vezes de castigo, acompanhando a leitura dos outros. [...] Todo esse livro delicioso me chamava para as suas páginas. [...] o Coração estremecia a nossa sensibilidade de meninos, nos interessava naqueles conflitos que eram os nossos. Este livro de tanto amor à Itália me fez amar aos que eu não conhecia, aos estranhos, aos meninos sujos porque não tinham roupas limpas, aos heróis dos contos. (Rego, [1933]1977, p. 34-35).

O forte envolvimento subjetivo presente na leitura de Carlos de Melo, sua identificação com as personagens e sua dificuldade em traçar os limites entre ficção e realidade só foram possíveis pelo surgimento de um novo modelo de livro leitura, de que Coração é um exemplo: o das narrativas escolares (Batista; Galvão, 2009).

Nas palavras de Olavo Bilac e Manuel Bomfim ([1910]1953), em seu prefácio ao livro Através do Brasil, esse novo modo de se dirigir à criança assim se caracterizaria:

Suscitar a coragem, harmonizar os esforços, e cultivar a bondade, - eis a formula da educação humana. 0s heroes principaes d'estas simples aventuras, não os apresentamos, está claro, para que sejam imitados em tudo, mas para que sejam amados e admirados no que representam de generoso e nobre [...]. Não se pode influir efficazmente sobre o espirito da criança e captar-lhe a atenção, sem lhe falar ao sentimento. Foi por isso que demos ao

4. Para conhecer outros relatos, ver o de Graciliano Ra$\operatorname{mos}([1946] 2002)$.

5. Antes de passar ao Coração, a personagem lia a série graduada de leitura de Felisberto de Carvalho (1934), cujas primeiras edições são do início da década de 1890 , baseadas no modelo enciclopédico das leituras instrutivas. nosso livro um caracter episodico, um tom dramatico para despertar o interesse do alumno e conquistar-lhe 0 coração. A Vida é acção, é movimento, é drama. (Bilac; Bonfim, 1953, p. 7-8, grifos meus)

É no quadro desse novo modelo de livro de lei- 
tura - em que se fala ao "sentimento" da criança para "influir eficazmente sobre [seu] espírito" - que a tematização da dor, da ausência de remissão diante da falta, do desamparo e da morte parece assumir relevância. Segundo as irmãs Adelina Lopes Vieira e Júlia Lopes de Almeida, no prefácio a seu livro Contos infantis em verso $e$ prosa (1910), a tematização do desamparo visaria criar uma "simpatia" "com os que sofrem", que resultaria, por sua vez, numa "paixão" ou "afeição" à "grande família dos infelizes" (Vieira; Almeida, 1910, p. 9). As autoras querem oferecer aos leitores, por meio dos textos, possibilidades de despertar o amor (a "simpatia"), para, assim, promover um laço ou vínculo, baseado no mecanismo da identificação (ou o "amor" e a "admiração" a que se referem Bilac e Bomfim) com aqueles que padecem.

Talvez, de fato, o que mais haja no cânone escolar republicano é quantidade de infelizes (e a intensidade da infelicidade) nos livros de leitura para crianças: os velhos resignados diante da morte e do abandono, as indefesas crianças pobres e sem ter o que comer, os animais que trabalham sob os maus tratos de seus donos, o pássaro cativo, a noite ameaçadora, a borboleta aprisionada por um menino, a morte de um ente querido.

Por que oferecer tanta dor e infelicidade em livros infantis? Por que fazer - e com tal intensidade - os meninos e as meninas sentirem-se como (pela identificação e pelo amor) esses personagens acometidos pela dor? Como esses elementos podem servir a um efeito de aculturação?

\section{Plutão}

“Plutão" é um dos poemas que integram a coletânea Poesias infantis, de Olavo Bilac ([1904]1943). Embora a obra escolar do prestigiado poeta parnasiano brasileiro venha sendo exaustivamente estudada, o poema é pouco explorado, talvez por não se articular muito claramente à temática nacionalista e republicana que vem servindo como chave principal para a interpretação de sua literatura didática. Não encontrei referências ao poema no trabalho de Marisa Lajolo (1982) voltado para o estudo da obra escolar de Bilac, mesmo quando ela apresenta a organização temática de Poesias infantis e explicita os agrupamentos, segundo esse critério, dos poemas que compõem a antologia. Essa característica díspar do poema é indicada por Andrea Cordeiro (2005), justamente quando discute a categorização temática do livro proposta por Marisa Lajolo. Para Andrea Cordeiro, “Plutão”, assim como outros poemas, seria "avulso", não integrando a organização temática, mas, ao mesmo tempo, servindo a 
ela. O poema, em minha opinião, é um dos textos que, pertencentes ao novo códice republicano, querem fazer o leitor integrar-se à "comunidade dos infelizes": ${ }^{6}$

Plutão

Negro, com os olhos em brasa,

Bom, fiel e brincalhão,

Era a alegria da casa

0 corajoso Plutão.

Fortíssimo, ágil no salto,

Era o terror dos caminhos,

$\mathrm{E}$ duas vezes mais alto

Do que seu dono Carlinhos.

Jamais à casa chegara

Nem a sombra de um ladrão;

Pois fazia medo a cara

Do destemido Plutão.

Dormia durante o dia,

Mas, quando a noite chegava,

Junto à porta se estendia,

Montando guarda ficava.

Porém Carlinhos, rolando

Com ele às tontas no chão,

Nunca saía chorando

Mordido pelo Plutão...

Plutão velava-lhe o sono,

Seguia-o quando acordado:

0 seu pequenino dono

Era todo o seu cuidado. 
Um dia caiu doente

Carlinhos... Junto ao colchão

Vivia constantemente

Triste e abatido, o Plutão.

Vieram muitos doutores,

Em vão. Toda a casa aflita,

Era uma casa de dores,

Era uma casa maldita.

Morreu Carlinhos... A um canto,

Gania e ladrava o cão;

E tinha os olhos em pranto,

Como um homem, o Plutão.

Depois, seguiu o menino,

Seguiu-o calado e sério;

Quis ter o mesmo destino:

Não saiu do cemitério.

Foram um dia à procura

Dele. E, esticado no chão,

Junto de uma sepultura,

Acharam morto o Plutão.

Esse poema que tematiza a morte desenvolve-se com base num esquema narrativo: as seis primeiras estrofes apresentam as personagens e a situação que será desestabilizada, a partir da sétima estrofe, pela doença e pela morte de Carlinhos; o décimo e último conjunto de versos traz a resolução ou o desfecho dados ao desequilíbrio que motiva a narrativa. Penso que é importante ressaltar a inter-relação entre essas três partes. Por um lado, constituem os elementos básicos do esquema narrativo; por outro, e mais importante, é a partir da expectativa gerada por esse esquema (que se ativa assim que

6. Para uma síntese da história editorial do poema, bem como para sua recepção contemporânea, ver Batista (2009a). Na transcrição do poema, que apresento a seguir, baseio-mena15ª edição, de1943.Aortografiafoiatualizada. 
se reconhece tratar-se de uma sequência narrativa) que um leitor lê, em geral, um texto desse tipo: suas perguntas - não nos podemos esquecer de que a leitura ocorre no tempo, a partir de cada conjunto de informações dadas e por sua integração progressiva a informações novas - serão organizadas em torno de expectativas sobre o que ocorrerá, sobre o que desestabilizará uma situação e sobre como será resolvido o conflito que desencadeará a ação.

Vou me concentrar inicialmente na primeira parte: é por meio dela que se instala um pacto de leitura (Mucci, 20-?) ou os movimentos do narrador, que buscam, pelo texto, posicionar o leitor em relação à narrativa. Para isso, dois elementos podem servir de ponto de partida. Primeiramente, essa parte inicial tem uma natureza predominantemente descritiva: apresentam-se Plutão e as ações que caracterizam a personagem por meio de sua relação com seu dono. Essa descrição é feita, em segundo lugar, por uma enunciação que, situada no presente, insere Plutão num tempo pretérito: a personagem "era" "a alegria da casa", "era” "o terror dos caminhos". 0 uso do verbo permite ao leitor uma antecipação ou uma expectativa em relação ao desequilíbrio que constituirá a narrativa, assim como a seu desfecho: o herói não será mais (na narrativa), por alguma razão, a "alegria da casa”, nem "o terror dos caminhos". 0 leitor não deve ter - o tempo verbal o marca - qualquer ilusão a respeito de um destino positivo para Plutão.

É interessante observar que, na primeira estrofe, o deslocamento para a esquerda da intensa adjetivação em torno da qual se caracteriza Plutão (à qual voltarei) destaca o uso do verbo no pretérito imperfeito, servindo a um efeito de mudança mais repentina das possíveis expectativas prévias do leitor: no mundo ficcional que se pretende que ele estabeleça, há um herói chamado Plutão, que tem como atributos ser "negro, com os olhos em brasa”, assim como "bom, fiel e brincalhão", mas esse herói não mais continuará assim, já que "era”. Podemos perceber a força desse mecanismo que reorienta o horizonte de expectativa do leitor, se temos em mente uma estrutura sintática em que a adjetivação está à direita: "Plutão era negro, com os olhos em brasa”. Instaurada como uma enunciação sobre episódios pretéritos a respeito de um herói que já não o é, uma tensão sobre o destino negativo de Plutão também se instaura, assim, desde a leitura dos primeiros versos do poema.

Não se trata de uma tensão qualquer, mas de uma tensão emocional. 0 poema oferece, assim, desde o início, uma possibilidade (uma "armadilha") de leitura organizada na busca de compreensão do que se passará (de negativo) com uma persona- 
gem (caracterizada positivamente). Além disso, propõe a construção de um mundo ficcional que não o separa, como ficção, da realidade, pela ausência de "enquadramentos" mentais que situariam a narrativa na ordem de um gênero baseado num distanciamento entre o narrado e o vivido. Esse mundo ficcional não é, por exemplo, situado num mundo circunscrito pela introdução de marcas de fabulação, de narrativas mágicas ou "de fadas"; ou de "lições" próprias à tradição da enunciação escolar para a criança (seja pela presença de um "eu" que explicitamente fala a um "vós" ou "tu" também explícito; seja pela enunciação clara de uma lição, ilustrada por exemplos) A ausência de marcadores de gêneros tradicionais infantis ou escolares deixa ao leitor também a liberdade (e a tarefa) de - à medida que lê - construir, com o que sabe e com o que é, o mundo ficcional e o processo enunciativo. Nada cria, portanto, um distanciamento ou algum tipo de estranhamento entre o leitor e o texto, o narrado, as personagens.

Pelo contrário: há sempre proximidade, instaurada não só pela natureza familiar (trata-se, como destaquei, de um mundo como o mundo real) dos eventos e das personagens, como por uma clara manifestação do ponto de vista do narrador sobre a personagem central. Esse ponto de vista se explicita pela forte adjetivação que cerca Plutão: “negro, com os olhos em brasa”, "bom fiel e brincalhão", “alegria da casa”, “corajoso Plutão". Como podemos constatar, as adjetivações, todas elas retiradas da primeira estrofe, mostram a extensão de seu uso: é toda a estrofe organizada em torno desse mecanismo, que assume a forma de epítetos, ou de expressões adjetivas que tendem a deslocar a atenção do ser (“Plutão") para seu atributo, favorecendo, por isso, a substituição do nome pelo atributo. A adjetivação é sempre, como já indiquei, positiva: os epítetos e as ações - embora sua extensão - podem ser reduzidos a uma matriz baseada numa oposição entre "dentro" e "fora”, ou "casa” e "exterior". A um "de fora” ou para um "externo" ponto de vista, Plutão é ameaçador. Seu nome é o do deus dos infernos, do mundo sombrio, do planeta mais distante e frio; mesmo que o leitor não atente a essa referência erudita, sua caracterização evidencia sua natureza sombria e ameaçadora: "negro, com os olhos em brasa"; "terror dos caminhos"; "fortíssimo, ágil no salto"; "duas vezes mais alto/ do que seu dono Carlinhos"; "fazia medo a cara". A um "de dentro" ou a um observador "interno", "de casa”, os atributos são inversos: "bom, fiel e brincalhão";

7. Como exemplificam, no primeiro caso, diferentes poemas do próprio Bilac. É o caso do conhecido "A Pátria": "Ama, com fé e orgulho, a terra em que nasceste!/ Criança! não verás nenhum país como este!” (Bilac, [1904]1943, p.63). Para uma exemplificação de procedimentos retóricos que organizam a lição pela abundância de exemplos, ver Batista (2009b, 2009c). 
"alegria da casa". Essa matriz opositiva tem como base ou ponto de ancoragem a identificação do ponto de vista do narrador - que desencadeia a descrição e o sistema de adjetivação - com aquilo que é Plutão para Carlinhos na relação ou na mediação que a personagem central estabelece entre seu dono e o exterior; ou entre o menino e as características que tornam Plutão apto a realizar essa mediação.

O "de fora" é ameaçador: Plutão protege de uma ameaça que há nos "caminhos", conjurando-a, já que deles é o "terror”; já que afasta a "sombra de um ladrão”; já que "montando guarda ficava". A casa precisa ser protegida de algo. Durante o dia, seu dono é "todo o seu cuidado", porque algo o expõe ao perigo, e isto mesmo no espaço "interno", uma vez que até no sono (esse espaço mais interno do interno), Plutão "vela" por seu dono. É interessante que tudo o que é ameaçador, com exceção dos possíveis ladrões, não é muito preciso ou explicitado (e, por isso, mais ameaçador); e deve ser apreendido por um processo de projeção, pelo leitor, de seus próprios medos e angústia, o que lhe deixa a iniciativa na definição do objeto de ameaça.

Carlinhos, por isso e necessariamente, está sempre exposto a esse algo que ameaça e, assim, traz medo, traz angústia (sobretudo angústia, esse medo sem objeto claro) ${ }^{8}$. É, por essa razão, apresentado ou dado a ver pelo leitor pelo signo da fragilidade. 0 dono de Plutão é uma criança, como os leitores o são; é designado pelo diminutivo familiar e afetivo; pode chorar (como resultado hipotético de uma brincadeira com Plutão); é seu "pequenino" dono. Aqui, mais uma vez, o texto está aberto à iniciativa do leitor: não se explicita que Carlinhos é uma criança. É a partir da apresentação da personagem (tendo em vista sua relação com Plutão) que o leitor deve inferir que o é e que, nessa condição, é frágil, mas possui o cão, e este por ele vela e dele cuida, protegendo-o do ameaçador.

Essa descrição do modo de organização da primeira parte do texto parece-me ter evidenciado alguns dos elementos com base nos quais se busca formar o leitor; quer dizer, busca-se colocá-lo na posição adequada para receber os efeitos visados pelo texto e provê-lo dos instrumentos necessários para isso, por meio de um contrato de leitura. 0 mecanismo mais geral, parece-me, está baseado na busca de criação de uma adesão subjetiva e emocional do leitor ao texto (à narrativa e a seus personagens): propõe-se que se leia o texto para descobrir um destino, já antecipado como negativo, de um herói; incentiva-se o leitor a não construir um mundo ficcional distanciado do real - ao contrário, incentiva-se a 
da-se, para a própria leitura, que o leitor traga sempre algo de si para preencher as lacunas do texto: o equacionamento da infância à fragilidade, as vagas (mas prementes) ameaças que cercam o desamparo da criança e das quais o protege Plutão.

Além disso: no quadro dessa implicação subjetiva, esforça-se por dirigir o leitor a realizar uma identificação e uma adesão a um objeto idealizado. Por um lado, oferece-se Carlinhos como um objeto de identificação: como o leitor, ele é uma criança; como o leitor, ele é frágil e sujeito a uma ameaça constante; a ameaça que o cerca deve ser preenchida, já que vaga, com as ameaças que cercam o próprio leitor, preenchidas com seu medo ou angústia. Carlinhos é oferecido, assim, como um elemento capaz de posicionar o leitor mesmo no próprio interior da narrativa e, desse modo, não propriamente lê-la ou acompanhá-la, mas vivê-la. Por outro lado, porém, oferece-se, a esse leitor marcado pelo signo da fragilidade, certa segurança: há alguém que, assim como protege Carlinhos, também protege o leitor do medo e da angústia, por meio do amor e do cuidado. Toda a adjetivação positiva de Plutão - sua idealização construída na mediação que estabelece entre o dono (o leitor) e o mundo ameaçador - o oferece como aquele que ama e como aquele que é objeto de amor. Objeto que, antecipa a narrativa, não mais o será: que será, portanto, perdido. Tudo procura, assim, instalar o leitor numa posição tensionada ou dramática: ele está no interior da própria narrativa; ele a vive por intermédio de Carlinhos, com o qual se identifica; e por intermédio de Plutão, a quem ama por amá-lo e por defendê-lo de sua fragilidade diante do mundo. Mas essas defesas diante do mundo, desde a instalação do pacto ficcional, antecipa-se, serão perdidas.

Serão perdidas porque Plutão falhará em proteger de um oponente impossível de ser dominado: a doença e a morte. É essa falha diante do impossível e sua busca de superação que vão constituir o conflito em que se baseará a narrativa. A primeira parte é concluída por uma espécie de síntese que reforça o amor de Plutão por seu dono e os cuidados que são a expressão desse amor: "Plutão velava-lhe o sono,/ Seguia-o quando acordado:/ O seu pequenino dono/ Era todo o seu cuidado".

"Todo seu cuidado" é, porém, impotente diante da doença que - introduz abruptamente o verso que inicia a segunda estrofe - se abate sobre Carlinhos. As três estrofes iniciais que organizam a segunda parte se marcarão por uma estrutura que evidencia, por um lado, num crescendo, a ação de um inimigo ou oponente incontrolável e ao qual não se pode opor resistência; e, por outro lado, o progressivo efeito devastador, em Plutão e na casa que deveria proteger, de sua impotência diante desse inimigo. 
Observemos que os primeiros versos de cada uma das estrofes indicam a paulatina ação do oponente, e os finais, a progressiva impotência de Plutão: “Um dia caiu doente/ Carlinhos... Junto ao colchão/ Vivia constantemente/ Triste e abatido, o Plutão. Ou ainda: "Morreu Carlinhos... A um canto,/ Gania e ladrava o cão;/ E tinha os olhos em pranto,/ Como um homem, o Plutão".

Se o leitor se inseriu na narrativa de acordo com o pacto de leitura - organizado sob o signo da proximidade emocional, da implicação subjetiva por meio da identificação com Carlinhos e do amor de e por Plutão -, viverá, na leitura do poema, uma encenação e uma experiência de sua própria morte e de seu horror (daí a recusa e a forte experiência emocional negativa relatada por alguns de seus leitores, como Helena Jobim [1996], que relata, em sua biografia do irmão, o compositor Tom Jobim, ter sido "torturada" por ele com a leitura em voz alta do poema).

A falha de Plutão em proteger seu dono (diante do irremediável) dará origem, então, a uma busca de reparação e superação desse inimigo. A última estrofe da segunda parte indica a direção que o herói assumirá no enfrentamento de seu oponente: “Depois, seguiu o menino,/ Seguiu-o calado e sério;/ Quis ter o mesmo destino:/ Não saiu do cemitério".

Bilac, então, modifica o ponto de vista a partir do qual constrói a narrativa. Se antes seu olhar segue Plutão, na estrofe seguinte acompanhará aqueles que dão falta de sua presença na casa ("Foram um dia à procura/Dele [...]", deixando em suspensão (e aumentando assim a tensão emocional) o ponto em que se encontrava a narrativa e que fazia o leitor antecipar a forma de superação que a personagem realizaria de sua falha: "Quis ter o mesmo destino:/ Não saiu do cemitério”: “... E, esticado no chão, [...] Acharam morto o Plutão.”

Diante da morte, a única forma de reparação possível é o próprio sacrifício, seguido da morte de Plutão. Por meio dela, a personagem reafirma seu amor e os princípios que governam sua relação com seu dono - que podem ser resumidos nas palavras “proteção”, “cuidado”, “lealdade”, “fidelidade”. Aquilo que era para o leitor um objeto de amor é, então, ao mesmo tempo, perdido e reencontrado. Identificado com Carlinhos por um desejo de assumir a mesma posição (a de alguém que, contra as ameaças e os perigos do mundo, tendo em vista sua fragilidade, é protegido por Plutão), o leitor vive a reparação da falha da personagem, recebe sua compensação (baseada no autossacrifício por um ideal - o amor, a lealdade e a fidelidade a seu dono). Tal como nos processos de "estar amando" e de luto descritos por Freud ([1921]1996b, 
[1917]1996c), o objeto de amor - roubado pela morte - pode ser reencontrado, se introjetado pelo leitor; se sua "sombra" cai sobre seu eu; se ao eu se integra na forma de um ideal, com o qual passa a se identificar. Não se trata mais da mesma identificação com Carlinhos, organizada pelo desejo de assumir sua posição. Trata-se, agora, de uma identificação distinta: a de ser como Plutão, cujas características ou atributos (o amor, a fidelidade, a luta contra o externo, na proteção do dono e da casa) se tornam um ideal para o próprio eu e aquilo que - segundo Freud ([1921]1996b) - fundamenta o laço social.

Sob um ponto de vista durkheimiano, o que o poema propõe, assim, a seu leitor, é - pela tematização (e experiência) da morte - "fazer-lhe tomar consciência de seu estado de dependência e de inferioridade naturais" e sua fragilidade e contingência, mas, ao mesmo tempo, "por meio de uma representação sensivel”, fazer-lhe perceber que, no laço com o outro, articulado em torno de ideais como o amor, o cuidado e a fidelidade - quer dizer, nos ideais de uma coletividade -, encontra uma resposta a seu desamparo individual (Durkheim, [1895]2005, p.124). Pode pertencer, agora, à mesma "família dos infelizes".

\section{Conclusão}

A “retórica da infelicidade" baseia-se, portanto, não apenas numa temática sobre o desamparo, mas também em mecanismos discursivos que buscam promover uma leitura "simpática", isto é, baseada na identificação do leitor com personagens do texto, que o leva a "viver" e a "experienciar" a narrativa. Trata-se justamente do tipo de leitura que as "artes de ler" (ver, por exemplo, Viana, 1949) não recomendam aos leitores adultos, pois estas pregam a necessidade de uma relação distanciada, baseada no julgamento moral, na escolha parcimoniosa dos títulos e na recusa à empatia e à identificação. Não se trata, tampouco, da leitura que se firma na escola secundária, calcada no estudo e na análise de textos literários (Razzini, 2000). Os escritores dos livros para as crianças, buscando formar seu espírito, produziram textos que ensejaram um modo novo de ler na escola, passível de fazer com que, de fato, os textos se gravassem na mente das crianças.

Textos, portanto, podem exercer um poder formativo. Esse poder, entretanto, não se exerce per se, como muitas vezes se supunha nos estudos sobre seu caráter ideológico. Analisei aqui uma das formas por meio das quais exerciam esse poder: os procedimentos retóricos que buscavam construir uma leitura do texto. Os fundamen- 
tos dessa análise estão baseados na ideia, defendida, entre outros, por Umberto Eco (1986), de que todo texto supõe um leitor e seus movimentos cooperativos como condição mesma para sua produção. A fim de orientar suas estratégias textuais, o produtor de um texto utiliza como ferramenta uma hipótese de leitor, ou um "leitor-modelo": um conjunto de previsões ou suposições a respeito das competências, das disposições e das crenças de seus leitores (como numa estratégia militar ou de xadrez). Ao mesmo tempo, porém, ainda segundo Umberto Eco (1986), pressupondo certa distância entre as condições de seu leitor e seu leitor-modelo, o produtor do texto não se restringe a prever um leitor. Ele busca também tanto produzir esse leitor quanto instituir sua leitura, e o faz por meio das estratégias textuais ou procedimentos retóricos. Em outras palavras: antecipando alguma distância, na situação concreta de leitura, entre o leitor visado e o leitor empírico, o produtor do texto busca contribuir para formá-lo como tal, isto é, como leitor, assim como para constituir sua leitura, fornecendo os elementos para criar a leitura desejada; e, desse modo, assegurar que os efeitos visados sobre o leitor se realizem. Dentre esses efeitos está o de aculturação: sua inserção numa comunidade de leitores e num determinado espaço social, tal como representado e apresentado pelos "fazedores" dos livros.

\section{Fontes e livros escolares citados}

BILAC, O. Poesias infantis. 15. ed. Rio de Janeiro: Francisco Alves, 1943. [1904].

BILAC, O.; BOMFIM, M. Através do Brasil. 40. ed. Rio de Janeiro: Francisco Alves, 1953 [1910].

CARVALHO, F. Primeiro livro de leitura. 119. ed. Rio de Janeiro: Paulo de Azevedo \& Cia., 1934 .

DE AMICIS, E. Coração. Trad. João Ribeiro. Rio de Janeiro: Francisco Alves, [19-?].

JOBIM, H. Antonio Carlos Jobim: um homem iluminado. Rio de Janeiro: Nova Fronteira, 1996.

RAMOS, G. Infância. 35. ed. Rio de Janeiro: Record, 2002.[1944].

REGO, J. L. Doidinho. Rio de Janeiro: José Olympio, 1977.[1933]. 
VIANA, M. G. A arte da leitura. Porto: Educação Nacional, 1949.

VIEIRA, A. L.; ALMEIDA, J. L. Contos infantis em verso e prosa. 8. ed. Rio de Janeiro: Francisco Alves, 1910.

\section{Referências bibliográficas}

BATISTA, A. A. G. A. Leitura escolar e aculturação: a "comunidade dos infelizes". Lectura y vida - International Reading Association, Buenos Aires, v. 30, p. 14-31, 2009 a.

BATISTA, A. A. G. Dos papéis velhos aos manuscritos impressos: paleógrafos ou livros de leitura manuscrita. In: BATISTA, A. A. G.; GALVÃO, A. M. O. Livros escolares de leitura no Brasil: elementos para uma história. Campinas, SP: Mercado de Letras, 2009b. p.153-178.

BATISTA, A. A. G.; GALVÃO, A. M. O. Livros de leitura: uma morfologia. In: BATISTA, A. A. G.; GALVÃO, A. M. O. Livros escolares de leitura no Brasil: elementos para uma história. Campinas, SP: Mercado de Letras, 2009c. p.75-104.

CORDEIRO, A. B. Dando vida a uma raiz: o ideário pedagógico da Primeira República na poesia infantil de Olavo Bilac. Dissertação (Mestrado em Educação) - Curso de Pós-Graduação em Educação, Universidade Federal do Paraná, Curitiba, 2005.

DURKHEIM, E. As regras do método sociológico. São Paulo: Martin Claret, 2005 [1895].

ECO, U. Lector in fabula: a cooperação interpretativa nos textos narrativos. São Paulo: Perspectiva, 1986.

FARIA, A. L. G. O trabalho: uma análise da ideologia do livro didático. Dissertação (Mestrado em Educação) - Universidade Federal de São Carlos, São Carlos, SP, 1980. Publicada como A ideologia no livro didático. 12. ed. São Paulo: Cortez, 1996.

FISH, S. Is There a Text in This Class? The Authority of Interpretive Communities. Cambridge, MA: Harvard University Press, 1980.

FREUD, S. Inibições, sintomas e ansiedade. Rio de Janeiro: Imago, 1996a. p.91-171. [1926]. (Coleção edição standard brasileira das obras completas de Sigmund Freud).

FREUD, S. Luto e melancolia. Rio de Janeiro: Imago, 1996c. p.245-266. [1917]. (Coleção edição standard brasileira das obras completas de Sigmund Freud).

FREUD, S. Psicologia de grupo e análise do ego. Rio de Janeiro: Imago, 1996b. p.79-154. [1921]. (Coleção edição standard brasileira das obras completas de Sigmund Freud).

LAJOLO, M. Usos e abusos da literatura na escola: Bilac e a literatura escolar na República Velha. Porto Alegre: Globo, 1982. 
MUCCI, L. I. Pacto narrativo. In: CEIA, Carlos. E-dicionário de termos literários. Disponível em: 〈http://www2.fcsh.unl.pt/edtl/verbetes/P/pacto-narrativo.htm〉. Acesso em: 01 abr. 2009.

NOSELLA, M. L. C. D. As belas mentiras: a ideologia subjacente aos textos didáticos. São Paulo: Cortez \& Moraes, 1979.

RAZZINI, M. P. G. O espelho da Nação: a “Antologia Nacional” e o ensino de português e literatura (1838-1971). Tese (Doutorado em Estudos da Linguagem) - Instituto de Estudos da Linguagem, Universidade Estadual de Campinas, Campinas, SP, 2000.

Recebido em 29 de março de 2012 e aprovado em 11 de maio de 2012. 